\title{
Complutum
}

ISSN: 1131-6993

\section{La valorización del yacimiento arqueológico de la Motilla del Azuer (Daimiel, Ciudad Real) a través de las nuevas tecnologías}

\author{
Miguel Torres Mas ${ }^{1}$, Julio López Tercero ${ }^{2}$, Víctor Manuel López-Menchero Bendicho ${ }^{3}$ Juan Torrejón \\ Valdelomar ${ }^{4}$, Herbert D.G. Maschner ${ }^{5}$
}

Recibido: 26/03/2021 / Aceptado: 04/08/2021

Resumen. La aplicación de nuevas tecnologías en el campo del patrimonio arqueológico está generando la incorporación de diferentes perspectivas con respecto a su proyección, puesto que por un lado permite recoger datos desde distintas lecturas y niveles, al tiempo que ofrece fórmulas novedosas en relacion a su valorización integral.

En las siguientes líneas se va a efectuar una descripción pormenorizada de los diferentes trabajos llevados a cabo dentro de la actividad "Motilla Virtual". Este proyecto se desarrolla a partir de un conjunto de actuaciones que van desde la digitalización 3D de todo su recinto, el diseño de una visita a través de realidad virtual, estudios de termografía y geofísica de todo el conjunto, así como trabajos de reconstrucción virtual del asentamiento durante la Edad del Bronce. De igual manera, se presentan de forma detallada los métodos elegidos, recursos empleados y resultados obtenidos, describiendo todos los aspectos o utilidades que se han puesto en funcionamiento dentro de este proyecto. Estas herramientas han permitido avanzar en la investigación, documentación, conservación y valorización de este monumento prehistórico.

Palabras Clave: patrimonio arqueológico, digitalización, reconstrucción virtual, realidad virtual, patrimonio digital, arqueología virtual.

\section{[en] Valorization of the archaeological site of Motilla del Azuer (Daimiel, Ciudad Real) through new technologies}

Abstract. The application of new technologies in the field of archaeological heritage is generating a suite of new
dialogues regarding its presentation. This is occurring because these technologies collect data that can be interpreted or
read at many different levels, offering novel and unique formulas for conducting comprehensive valuations.
Taking this approach, a detailed description of the developments and results carried out within the creation of the "Virtual
Motilla" is reviewed in this paper. The project developed from a set of projects that begin with the 3D digitization of
the entire site, and then progress to the design of a visit through Virtual Reality, thermography and geophysical studies
of the entire complex, and ultimately, virtual reconstructions of the settlement during the Bronze Age. The chosen
methods, resources used, and results are presented in detail, describing all the methods and technologies used in this
project. These tools have made it possible to advance the research, documentation, conservation and valorisation of this
important and unique prehistoric monument. Key Words: archaeological heritage, digitization, virtual reconstruction, virtual reality, digital heritage, virtual archaeology.

Sumario. 1. La representatividad de las Motillas de la Edad del Bronce de La Mancha. El caso de la Motilla del Azuer. 2. El proyecto "Motilla Virtual". 3. Trabajos de digitalización en la Motilla del Azuer. 4. Estudio termográfico del ámbito arqueológico. 5. Prospección geofísica y reconstrucción virtual de estructuras. 6. Proyecto de realidad virtual: los sistemas head mounted display. 7. Características básicas del software de realidad virtual. 7.1. Sistemas de locomoción. 7.2. Mecánicas de interacción e interfaces. 7.3. Calidad gráfica y sonora. 8. Conclusiones. Bibliografía.

\footnotetext{
1 Yacimiento arqueológico Motilla del Azuer/Ayuntamiento de Daimiel, c/Luis Ruiz Valdepeñas nº 6, $3^{\circ}$ B, 13250 Daimiel (Ciudad Real),motilladelazuer@aytodaimiel.es.

Myou Software, c/Francisco Fernández Ordóñez n 7, Bajo B, 13710 Miguelturra (Ciudad Real), myousoftware@gmail.com Global Digital Heritage Spain, victor.lopezmenchero@gmail.com.

Torrejón Estudio, c/Cruz del Sur, Bloque 5, 2 E, 13005 Ciudad Real, j.torrejon.valde@gmail.com.

Global Digital Heritage USA, maschner@globaldigitalheritage.org.
} 
Como citar: Torres Mas, M. et al. (2021): La valorización del yacimiento arqueológico de la Motilla del Azuer (Daimiel, Ciudad Real) a través de las nuevas tecnologías. Complutum, 32(2): 525-541.

\section{La representatividad de las Motillas de la Edad del Bronce de La Mancha. El caso de la Motilla del Azuer}

La Motilla del Azuer está localizada a unos 10 $\mathrm{km}$ al este del casco urbano de Daimiel (Ciudad Real), situándose en el interior de la vega del río homónimo. El número de intervenciones realizadas en su recinto han convertido a este conjunto en el testimonio más representativo de una tipología de yacimientos excepcionales conocidos como motillas: asentamientos singulares dentro de la fase crono-cultural de la Edad del Bronce en La Mancha (2200-1500 a.n.e.). En virtud de sus características y expresiones materiales asociadas fue una etapa que ostentó personalidad y entidad cultural propia (Nieto y Sánchez-Meseguer 1988; Nájera y Molina 2004; Fernández-Posse y Martín 2007; Torres 2018; Nájera et al. 2019).

Grosso modo, las motillas fueron enclaves que contaron con potentes sistemas defensivos destinados al control y gestión de recursos críticos. Se emplazaron a lo largo de la llanura que forma La Mancha, correspondiendo con el único modelo de estas características configurado en la península ibérica durante este intervalo cronológico (Nájera y Molina 2004: 197). $\mathrm{Su}$ abandono generó unos montículos cónicos artificiales que son fácilmente reconocibles actualmente en el paisaje.

Las motillas buscaron en su disposición el dominio de una serie de ventajas naturales significativas: accesibilidad a recursos hídricos, como la cercanía a áreas fluviales y a los niveles freáticos subterráneos existentes en la comarca; terrenos fértiles para la práctica agropecuaria, y la vinculación con vías naturales. Por tanto, las gentes del Bronce buscaron una ubicación espacial estratégica para asegurar el compromiso de una ocupación a largo plazo, amortizando el esfuerzo de construir fortificaciones de gran complejidad. Así, en su interior fueron habilitadas unidades domésticas y salas de trabajo y almacenaje (Fernández-Posse y Martín 2007: 110). En algunos de estos núcleos se ha podido documentar la configuración del poblado al exterior del sistema defensivo (Nájera y Molina, 2004: 193-194; Fernández-Posse y Martín 2007: 110; Torres, 2015: 20).
La Motilla del Azuer es el único de estos establecimientos que cuenta con estudios sistemáticos desde que comenzaron las investigaciones arqueológicas en 1974, combinando en ellas labores de excavación, restauración y valorización (Nájera y Molina 2004; Martin et al. 2004; Nájera et al. 2012; Angulo 2018; Nájera et al. 2019; Torres et al. 2021). Estas intervenciones han aportado valiosas informaciones para avanzar en la interpretación de este contexto y en la definición de estos grupos humanos pretéritos.

Los trabajos emprendidos han permitido describir el monumento como una fortificación de planta central, constituida por tres líneas murarias concéntricas en torno a una torre de planta cuadrangular. A este ámbito se accedía mediante una serie de rampas y escaleras embutidas en pasillos, en relación a un sistema de pasadizos y puertas que proporcionaban un aspecto laberíntico a todo el sitio (Figura 1).

En líneas generales, esta fortificación fue destinada a la protección y control de artículos esenciales para esta sociedad: el agua, captada mediante un pozo excavado en el patio oriental; el almacenamiento y procesado de cereales a través de potentes silos; la estabulación ocasional del ganado, y la producción de cerámica y otros objetos artesanales. El pozo permitió el acceso a la masa de agua subterránea denominada Mancha Occidental mediante la perforación de la terraza aluvial, llegando a horadar en los propios niveles calizos del subsuelo (Nájera y Molina 2004: 184). Por sus dimensiones y complejidad constructiva esta infraestructura se ha convertido en el referente icónico de todo el conjunto.

Al exterior de este entramado defensivo se situaba el poblado, en un radio de unos $50 \mathrm{~m}$. A pesar de su identificación desde las primeras campañas, en estos momentos constituye el espacio peor conocido de toda el área arqueológica. No obstante, los trabajos acometidos han venido a señalar que, fundamentalmente, en torno a este ámbito se distribuyeron las viviendas de las gentes de la Motilla. Estas casas fueron levantadas con planta de tendencia oval o rectangular, erigidas con zócalo de mampostería de piedra caliza, alzados de barro con postes embutidos y techumbres de materiales de origen vegetal. En ocasiones se han documentado tabiques interiores y muros mediane- 


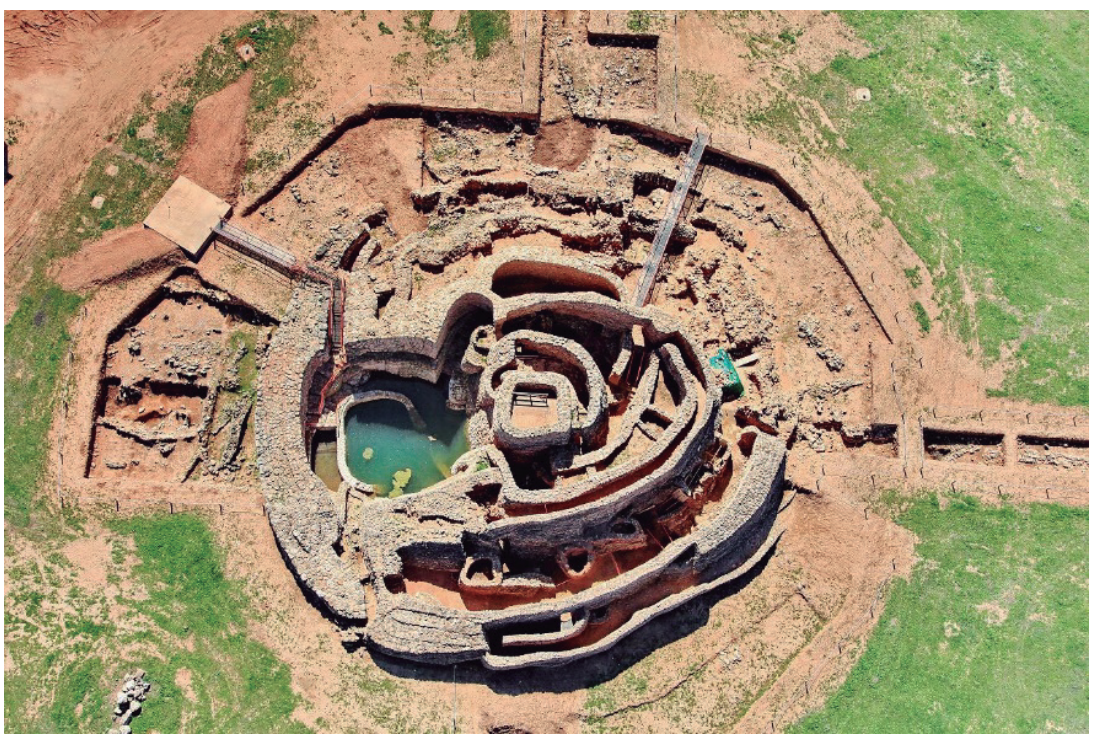

Figura 1. Vista aérea Motilla del Azuer. Fotografía Ayuntamiento de Daimiel.

ros (Nájera et al. 2012: 152). En este sector también se detectan dispositivos dedicados al almacenamiento de alimentos y otras funciones productivas, localizando en determinados puntos, como la zona septentrional, una alta concentración de fosas y restos de hogares y hornos (Nájera y Molina 2004: 195).

El mundo funerario advierte que las tumbas no constituyeron una necrópolis diferenciada, ya que la mayor parte de los enterramientos fueron dispuestos en relación al poblado, participando de un patrón generalizado en buena parte de la península ibérica durante esta etapa (Jiménez et al. 2008). El ritual empleado fue el de la inhumación individual, en posición decúbito lateral flexionada, colocando al difunto dentro de fosas simples o revestidas por muretes de mampostería o pequeñas lajas hincadas. Dentro de este ceremonial algunos individuos infantiles fueron depositados en el interior de vasijas cerámicas (Nájera et al. 2012: 158).

Las particularidades que atesora la Motilla del Azuer, junto con la monumentalidad advertida en sus estructuras, la cultura material exhumada en su registro arqueológico y la riqueza científica de sus expresiones, la han convertido en un activo valioso para su explotación como reclamo cultural y turístico de primer nivel. En virtud de la potencialidad que ostenta, el Ayuntamiento de Daimiel desde el año 2012 viene apostando decididamente por la adecuación y valorización integral de este conjunto ${ }^{6}$,

El yacimiento es de titularidad pública, perteneciendo a la Junta de Comunidades de Castilla-La Mancha, cediendo que además forma parte de la Red de Yacimientos Visitables de Castilla-La Mancha ${ }^{7}$. En los últimos años, como vamos a explicar pormenorizadamente en las siguientes páginas, se ha venido impulsando la incorporación de nuevos usos tecnológicos, aprovechando las posibilidades que ofrecen estos instrumentos para garantizar una gestión integral y una correcta toma de decisiones (López-Menchero 2012: 34).

\section{El proyecto "Motilla Virtual"}

La valorización integral de cualquier elemento del patrimonio cultural debe ser una premisa preferencial en la misión que adquiere este legado ante la sociedad. Igualmente, entre sus estrategias prioritarias debe situarse el impulso de acciones para el reconocimiento de los múltiples significados y particularidades que ostenta; al mismo tiempo que incentive la involucración de la ciudadanía en su mantenimiento y salvaguarda. Por estas razones, una dimensión fundamental en su gestión debe ser potenciar las iniciativas en torno a la investigación, conservación y difusión.

La incorporación de los últimos avances tecnológicos en este ámbito está implicando

temporalmente su gestión y explotación al Ayuntamiento de Daimiel por convenido suscrito el 8 de noviembre de 2012 y renovado en 2018 .

https:/cultura.castillalamancha.es/patrimonio/yacimientos-visitables 
la introducción de mejoras significativas en diversas áreas, con aportaciones sustanciales en la valorización de sus recursos. A este respecto, estas herramientas están suponiendo adelantos considerables en la documentación de los vestigios arqueológicos, facilitando las labores de estudio, interpretación y presentación.

El patrimonio cultural, al igual que sucede con el patrimonio natural, está cada vez más amenazado. Esta realidad resulta más evidente en conjuntos arqueológicos al aire libre que se encuentran expuestos de manera continua al deterioro paulatino de sus estructuras por la acción de la lluvia, la nieve, el hielo, el viento, el sol, el granizo, los microorganismos, el crecimiento de plantas infestantes, etc. En el caso de los yacimientos abiertos al público, a todos estos factores habría que sumar la acción de los propios visitantes que ejercen una presión pequeña pero constante sobre el bien (Merhav y Killebrew 1998). Es por ello, que muchos destinos turísticos tratan de establecer su capacidad de carga con el objetivo de minimizar los impactos negativos derivados de la excesiva afluencia de visitantes (García et al. 2014). La Motilla del Azuer no es una excepción. Lo intrincado de su diseño formado por pasillos estrechos con cambios constantes de dirección, así como escalones y rampas, provocan un contacto directo entre los visitantes y las paredes y suelos del conjunto. Esto también se traduce en dificultades de accesibilidad física que impiden a personas con movilidad reducida poder recorrer la totalidad del recinto fortificado. Junto al reto de la accesibilidad física surge también el reto de la accesibilidad intelectual, pues no resulta sencillo comprender los múltiples significados que encierra un enclave prehistórico como este. Para afrontar estos desafíos hasta la fecha se había optado por un sistema de visita guiada obligatoria, en donde las personas interesadas en conocer in situ el conjunto deben comprar sus entradas de forma anticipada a través de la página web http:/www.motilladelazuer.es. El número máximo de participantes por grupo habitualmente es de 24 personas, aunque durante la pandemia este ratio se ha visto reducido, variando el número según el contexto sanitario, con el objetivo de disminuir el riesgo de contagio por COVID-19. La visita guiada presenta múltiples bondades en relación a los retos anteriormente mencionados, pues permite controlar con total exactitud el número de visitantes que cada día y cada semana acceden al ya- cimiento, evita que los turistas abandonen los recorridos marcados y acondicionados, permite supervisar el adecuado comportamiento de todos los visitantes, $\mathrm{y}$, además, contribuye a revelar los significados ocultos de un lugar tan complejo como una fortificación en llano de la Edad del Bronce, pues no hay mejor herramienta interpretativa que un guía-intérprete (López-Menchero 2013: 94).

Pese a todo, esta estrategia también presenta debilidades, pues muchos turistas tienen noticia de su existencia una vez se encuentran en el destino, resultando casi imposible conseguir entradas con tan poco tiempo de antelación ante la gran demanda existente, que hace necesario reservar la visita con al menos un mes de antelación. Sin duda, la imposibilidad de conocer la motilla estando tan cerca genera frustración en muchos turistas cuya procedencia a veces es realmente distante, sin que hasta la fecha existiera ninguna alternativa. Tampoco existía ningún mecanismo para facilitar que las personas con movilidad reducida pudieran conocer el interior de la Motilla, dadas las complejas características del monumento. Precisamente para tratar de paliar estas debilidades surge el proyecto "Motilla Virtual" promovido por el Ayuntamiento de Daimiel, que pone en práctica algunas de las recomendaciones formuladas por la Organización Mundial del Turismo para gestionar los impactos negativos en el patrimonio derivados del turismo (WTO 2001: 5-7). Este proyecto, entre otros objetivos, persigue combinar la oferta real del monumento como destino físico con su oferta virtual impulsando su reconocimiento como recurso patrimonial y turístico de primer orden. En la misma medida, forma parte de una estrategia para impulsar su divulgación mediante el uso de tecnologías que abarcan los estudios termográficos, las prospecciones geofísicas 3D con georradar, la digitalización $3 \mathrm{D}$, las reconstrucciones virtuales y los sistemas de realidad virtual.

La compleja realidad que supone la activación de un programa de esta naturaleza obliga a que deba ser abordado desde la visión, aportación y cooperación de un conjunto amplio de especialistas de distintas disciplinas científicas, ya que su contribución genera un enriquecimiento completo de todas las fases de trabajo, otorgando una mayor calidad y rigurosidad al estudio final (López-Menchero et al. 2017). En este caso concreto se ha desarrollado un trabajo interdisciplinar gracias a la participación de arqueólogos, diseñadores gráficos, 
intérpretes del patrimonio, pilotos oficiales de drones, geofísicos e historiadores.

\section{Trabajos de digitalización en la Motilla del Azuer}

La primera actuación dentro del proyecto de aplicación de nuevas tecnologías en la Motilla del Azuer consistió en la realización de una campaña de digitalización 3D de toda la parte exenta del yacimiento arqueológico (Figura 2). Esta labor se pudo desarrollar gracias a la inestimable ayuda de la entidad estadounidense sin ánimo de lucro Global Digital Heritage (GDH), que de manera desinteresada aportó tanto un modelo fotogramétrico del recinto como un amplio repertorio de imágenes formado por fotografías 360 de gran calidad.

Para obtener el modelo fotogramétrico fue empleado el software comercial Reality Capture, que permite procesar grandes cantidades de imágenes a mayor velocidad que otros programas del mercado, al menos en el momento de realizar este proyecto, pues el sector de los programas de fotogrametría evoluciona de manera constante y vertiginosa dadas sus múltiples aplicaciones y su creciente conexión con el lucrativo mundo de los videojuegos. En el caso que nos ocupa fue necesario procesar varios miles de imágenes, circunstancia que explica la necesidad de contar con los programas más potentes disponibles en ese instante. El modelo 3D obtenido no ha sido utilizado únicamente para la experiencia de realidad virtual (RV), sino que además se encuentra disponible de manera gratuita en la página de GDH en Sketchfab (https://sketchfab. com/3d-odels/la-motilla-del-azuer-daimielspain-750c1dc950274be39705545f4a492bd9) (Figura 3).

Teniendo en cuenta la extensión y complejidad del yacimiento, así como la imposibilidad de que un visitante pueda recorrerlo por completo de forma virtual en un tiempo razonable, se optó por digitalizar con el mayor nivel de detalle posible dos sectores específicos del complejo prehistórico, concretamente los correspondientes al pasillo meridional en recodo y al gran pozo de agua. Estos dos lugares son los únicos que se pueden recorrer "andando" en la experiencia de RV; solución que aligera y simplifica el trayecto. No obstante, para complementar las labores de digitalización 3D y hacer accesibles aquellas zonas que no fueron digitalizadas con tanto nivel de detalle, se desarrolló una documentación específica del recinto mediante el uso de fotografía esférica 360 , usando para ello una cámara profesional Insta360 Pro dotada con 6 lentes, que recogió imágenes 360 3D 8K. A diferencia de otras cámaras esféricas, la posibilidad de tomar imágenes 360 3D permite su integración en sistemas de RV como este. Asimismo, las imágenes 360

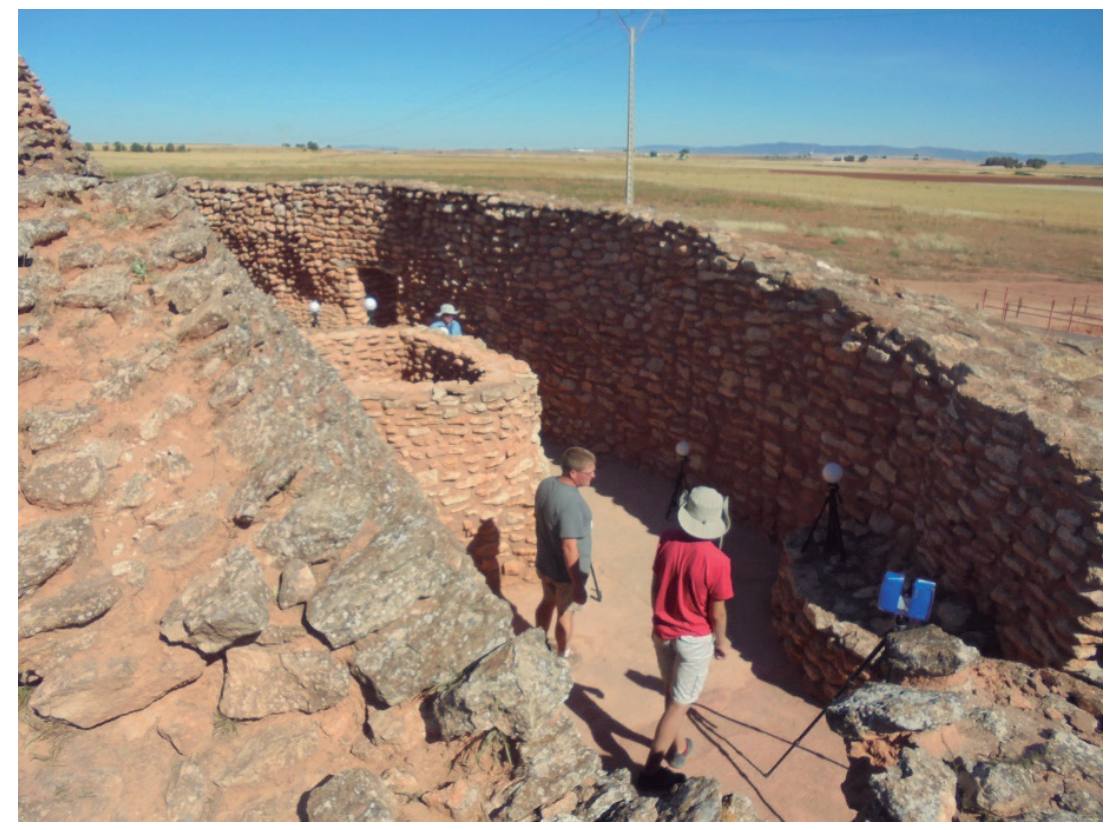

Figura 2. Labores de digitalización en el yacimiento. 
presentan un carácter complementario respecto a la representación fotogramétrica tridimensional, ya que permiten incorporar todo el paisaje circundante al emplazamiento. Por consiguiente, ofrecen una referencia contextual fotorrealista difícil de conseguir únicamente con el modelo tridimensional. En este sentido, aumentan el carácter inmersivo de la experiencia de RV, dando además acceso a aquellos ámbitos que han sido excluidos del recorrido virtual transitable.

La estrategia de digitalización ha sido diseñada en base al cumplimiento de unos objetivos concretos, en este caso vinculados con la puesta en marcha de un sistema virtual ad hoc, pues tal y como recomienda el punto 2 de los Principios de Sevilla": "Previamente a la elaboración de cualquier visualización asistida por ordenador siempre debe quedar totalmente claro cuál es la finalidad última de nuestro trabajo, es decir, cual es el objetivo final que se persigue alcanzar. Consecuentemente, diferentes niveles de detalle, resolución y precisión pueden resultar necesarios."

Es importante recalcar que estos trabajos de documentación y digitalización 3D han presentado un carácter no invasivo, siendo respetuosos en todo momento con la conservación del monumento. Se trata, por tanto, de técnicas sostenibles desde el punto de vista de su aplicación.

\section{Estudio termográfico del ámbito arqueológico}

Una de las actividades trazadas dentro del programa de integración de nuevos medios tecnológicos fue el desarrollo de un análisis termográfico sobre el recinto arqueológico. En buena medida, se buscaba aprovechar las posibilidades que ofrecen estos estudios para avanzar en la caracterización del monumento.

En líneas generales, la termografía es una técnica de inspección y diagnosis, no destructiva, que evalúa el comportamiento térmico de los elementos y su relación con las características materiales y estructurales de los mismos mediante la captación de la radiación electromagnética (Avdelidis y Moropoulou 2004). Esta emisión es transformada inicialmente en una señal eléctrica y convertida posteriormente en una imagen digital, empleando en este cometido cámaras térmicas o de termovisión. Concretamente, durante este proceso la radiación de calor es detectada electrónicamente, quedando representados sus valores diferenciales por medio de escalas de color en virtud

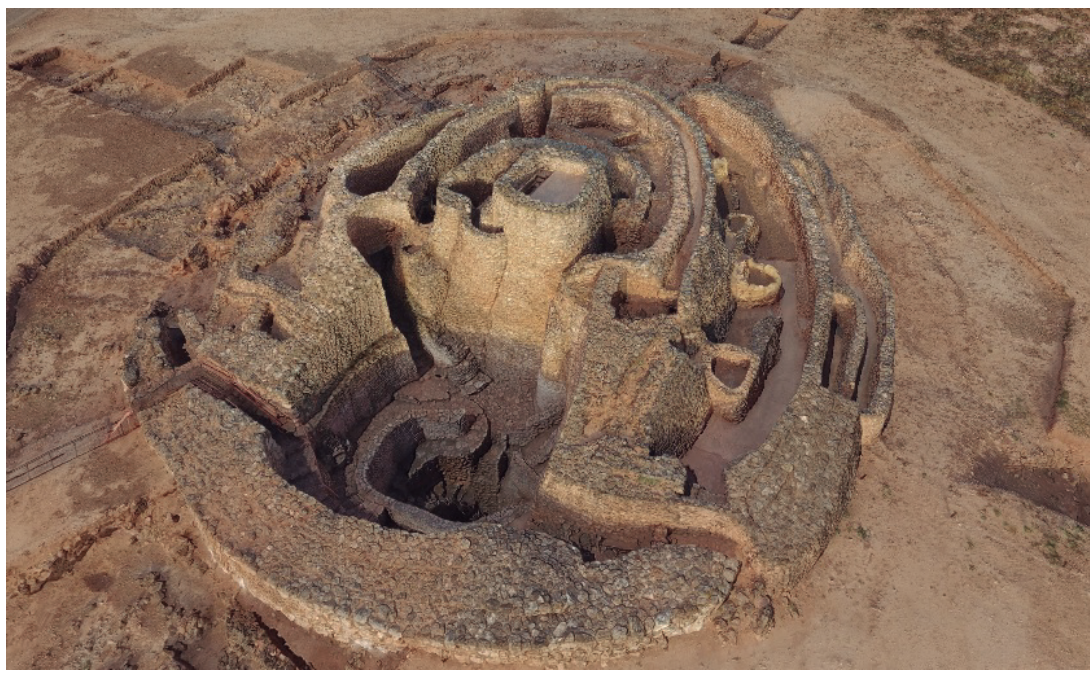

Figura 3. Vista Motilla del Azuer en plataforma Sketchfab.

Los Principios de Sevilla o Principios Internacionales de la Arqueología Virtual fueron elaborados bajo la coordinación de la Sociedad Española de Arqueología Virtual (SEAV) y del Comité Internacional de Documentación del Patrimonio (CIPA-ICOMOS) siendo ratificados por la $19^{\text {a }}$ Asamblea General de ICOMOS en Nueva Delhi en diciembre de 2017. 
del grado de temperatura: correspondiendo cada uno de los píxeles con un intervalo de medición. Es decir, a través de esta herramienta se pueden apreciar discontinuidades debidas a cambios de densidad y calor, ya que cualquier material cuenta con la capacidad de almacenar energía, produciendo una respuesta distinta a las variaciones térmicas en función de sus propiedades intrínsecas (Gómez-Heras 2012).

Estos datos son interesantes a la hora de evaluar las condiciones en las que se encuentra cualquier tipo de construcción, al determinar posibles patologías o discontinuidades existentes: filtraciones de agua, humedades, acumulaciones de aguas pluviales, etc. En el campo del patrimonio cultural ostenta una gran potencialidad debido a su naturaleza no invasiva y al diagnóstico que ofrece sobre su estado de conservación. Así, entre otras consideraciones, facilita la identificación de lesiones en muros y unidades constructivas; permite apreciar variaciones en las composiciones, o incluso puede llegar a describir estructuras no definidas en superficie (Lerma et al. 2013). Por lo tanto, es un instrumento bastante eficaz para conocer los procesos de deterioro que sufren los recursos culturales; siendo útil para enfocar tareas de restauración y en la adopción de medidas en materia de conservación preventiva. De igual manera, un análisis comparativo entre los resultados obtenidos mediante esta labor y los testimonios arqueológicos inferidos puede ayudar en la interpretación de los procesos históricos de cualquier conjunto. En definitiva, se trata de una metodología que cuenta con amplias posibilidades en su proyección, enriqueciendo las valoraciones establecidas sobre estas entidades.

En el caso de la Motilla del Azuer se ha pretendido aprovechar las ventajas que ofrece esta técnica para obtener información relevante sobre determinados contenidos, especialmente sobre las técnicas constructivas pretéritas y posibles alteraciones presentes. Stricto sensu, el objetivo principal de esta actuación fue el de conseguir evidencias sobre problemáticas relacionadas con la ascensión capilar, la pluviometría, la higroscopicidad o las condensaciones en el interior de los paramentos; patologías previamente documentadas en el yacimiento. Diagnosticar estos impactos ha orientado, en parte, las actividades de restauración emprendidas en los últimos años (Torres et al. 2021: 278-279).

El proyecto consistió en un estudio termográfico de una extensión de 1,4 ha, comprendiendo el recinto interior fortificado, la zona del poblado y el contorno más próximo al perímetro arqueológico 9 . Grosso modo, el dispositivo termográfico consigue que los objetos emitan una energía proporcional a la temperatura percibida en la superficie, aunque la cantidad real detectada depende del área seleccionada y del medio físico en el que se encuentra, por lo que es un aspecto que debe tenerse en cuenta.

La captura, desarrollada a través de varios vuelos, fue efectuada durante el mes de marzo de 2019. La fecha elegida fue clave en el procedimiento, puesto que los resultados varían considerablemente en función de la etapa del año escogida. Por esta razón, se estimó la idoneidad de llevarla a cabo al inicio de la primavera, coincidiendo con un período en el que la vegetación no está excesivamente alta, por lo que presenta unas condiciones muy propicias para alcanzar una evaluación satisfactoria. Durante la toma de datos cada pixel reflejado en la muestra obtuvo un valor de sistematización de la radiación, precisando la temperatura generada por cada componente. Recogida esta información, fue elaborado un mapa de imágenes con tonalidades distintas en virtud de la temperatura advertida (Figura 4).

Este procedimiento ha sido provechoso para obtener referencias importantes sobre el enclave: discontinuidades, materiales constructivos empleados y patologías no detectadas con anterioridad. Verbi gratia, se ha podido apreciar alteraciones relacionadas con la ascensión capilar o la acumulación de aguas pluviales en el sector meridional del recinto intermedio; daños que han sido corregidos con posterioridad mediante acciones de restauración específicas. Por consiguiente, esta investigación ha sido muy beneficiosa para avanzar en las operaciones de protección y salvaguarda del monumento. A este respecto, sería interesante repetir esta captura con cierta regularidad en los próximos años, al conseguir comparativas que nos indicarían la evolución de sus tramos.

\section{Prospección geofísica y reconstrucción virtual de estructuras}

Este trabajo estuvo comprendido dentro del proyecto "Investigación geofísica, sedimento-

Las labores de termografía fueron realizadas gracias a la empresa AvistadeRPaz y al piloto oficial con licencia de AESA Timoteo Úbeda, contando con un equipo formado por un dron DJI Inspire 1, con sensor termográfico y $4 k$. 


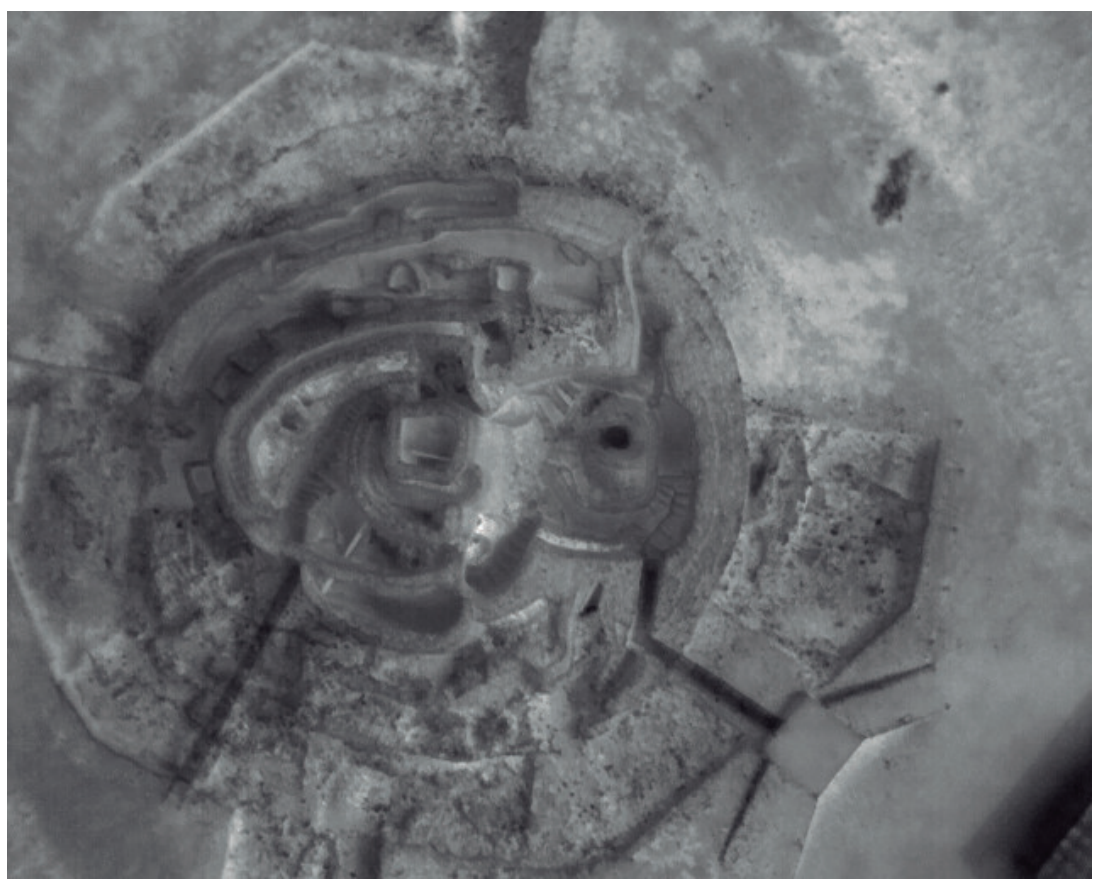

Figura 4. Mapa general a través de esta técnica en paleta de grises.

lógica y aplicación de nuevas tecnologías en la Motilla del Azuer (Daimiel, Ciudad Real)", dentro de la convocatoria de 2019 para "Proyectos de investigación del patrimonio arqueológico y paleontológico de Castilla-La Mancha" por parte de la Junta de Comunidades de Castilla-La Mancha ${ }^{10}$.

Para poder acometer esta actividad las operaciones contempladas han estado fundamentadas en pautas generales establecidas en este campo; así como una serie de planteamientos resultantes de experiencias puestas en marcha en otros sitios, cuyo objeto de estudio, fuentes y problemáticas son, a grandes rasgos, similares a los de este enclave de la Edad del Bronce (Torrejón et al. 2019; Lužnik-Jancsary et al. 2020).

Sin embargo, las particularidades mostradas en este bien han supuesto la necesidad de partir de unos condicionantes previos, sobre todo para lograr una correcta interpretación de los datos. El primero de ellos es la amplia secuencia arquitectónica que presenta; puesto que se trata de un complejo que contó con una ocupación que llegó a superar los ocho siglos, con una cronología con fechas calibradas que

10 Proyecto realizado bajo la dirección de Miguel Torres Mas, como Investigador Principal, y Rosa $\mathrm{M}^{\mathrm{a}}$ Mediavilla López; contando también con la participación de los investigadores: Juan Ignacio Santisteban Navarro, Silvino Castaño Castaño, Javier Vallés Iriso y Honorio Álvarez García. se sitúan entre el 2200 y el 1350 a.C. (Nájera et al. 2019). Además, su abandono hace un dilatado lapso de tiempo, junto con su ubicación al aire libre, ha condicionado su estado de conservación, provocando el deterioro significativo de algunas estructuras o la pérdida irreparable de otras (Angulo, 2018: 34-35). También hay que ser conscientes que corresponde con un ámbito intensamente estudiado, excavado y restaurado desde sus inicios, aglutinando en la actualidad testimonios pertenecientes a diferentes fases que son apreciados de manera simultánea. El segundo factor es el concerniente a las fuentes disponibles para llevar a cabo esta actuación: limitadas a la mencionada documentación 3D, la excavación arqueológica, y la prospección geofísica.

La excavación ha representado la base principal y punto de partida de las valoraciones inferidas en este proyecto, por lo que, en gran medida, ha venido a cristalizar los planteamientos estimados a lo largo de las múltiples investigaciones emprendidas. Para esta reconstrucción se ha prestado especial atención a los elementos exentos, puesto que han aportado una valiosa información acerca de las técnicas constructivas empleadas, tanto para el recinto fortificado como para el poblado alrededor del mismo.

Por su parte, los análisis geofísicos fueron ejecutados inicialmente durante las campañas 
de 2004 y 2009, si bien se extendieron únicamente sobre determinadas áreas concretas (Peña et al., 2009). En el 2019, en el marco del señalado proyecto de investigación se desarrolló una prospección geofísica sobre todo el sector más externo del conjunto, coincidente con la definida zona del hábitat (Nájera y Molina 2004: 193; Martin et al. 2004: 225; Nájera et al. 2012: 150; Torres 2015: 20). Debido a que se trataba del ámbito en el que se habían dedicado menos esfuerzos se estimó la idoneidad de orientar acciones que impulsaran la descripción de este perímetro (Figura 5). Asimismo, el carácter endeble de sus edificaciones había significado una peor conservación de sus estructuras, por lo que esta reconstrucción ha resultado interesante para avanzar en su comprensión.

La labor geofísica incluyó una superficie final de unos $9.700 \mathrm{~m}^{2}$, empleando un georradar multicanal de $600 \mathrm{MHz}^{11}$, con el que se realizaron un total de 311 transectos, adquiriendo 3421 secciones. Con el fin de facilitar la percepción de los resultados obtenidos se decidió plasmar una visualización 3D de los mismos, constituyendo esta representación la base del diseño de la hipótesis virtual.
A pesar de los relevantes testimonios alcanzados gracias a esta tarea, los datos mostraron ciertas carencias que necesitaron ser solventadas para conseguir una interpretación integral, especialmente aquellas alusivas al contexto doméstico del establecimiento. Para solucionar estas limitaciones nos hemos servido de paralelos de yacimientos coetáneos o con similitudes tipológicas: La Bastida (Totana, Murcia), Los Millares (Santa Fe de Mondújar, Almería) o Castellón Alto (Galera, Granada). Son entidades arqueológicas que tienen un largo recorrido en su valorización, llegando incluso a incorporar en su perímetro reconstrucciones materiales de sistemas defensivos o viviendas. A grandes rasgos, estas realidades han sido sustanciales para la propuesta elaborada en la Motilla del Azuer.

Una vez recogidos y examinados todos los detalles necesarios se pasó a representar gráficamente esta información. Para la visualización de las casas se ha optado por el patrón inferido en las investigaciones previas: zócalo de mampostería de piedra caliza, resto del alzado de la pared levantado con barro de la vega del río Azuer, y postes de madera embutidos. Los paramentos, tanto al exterior como

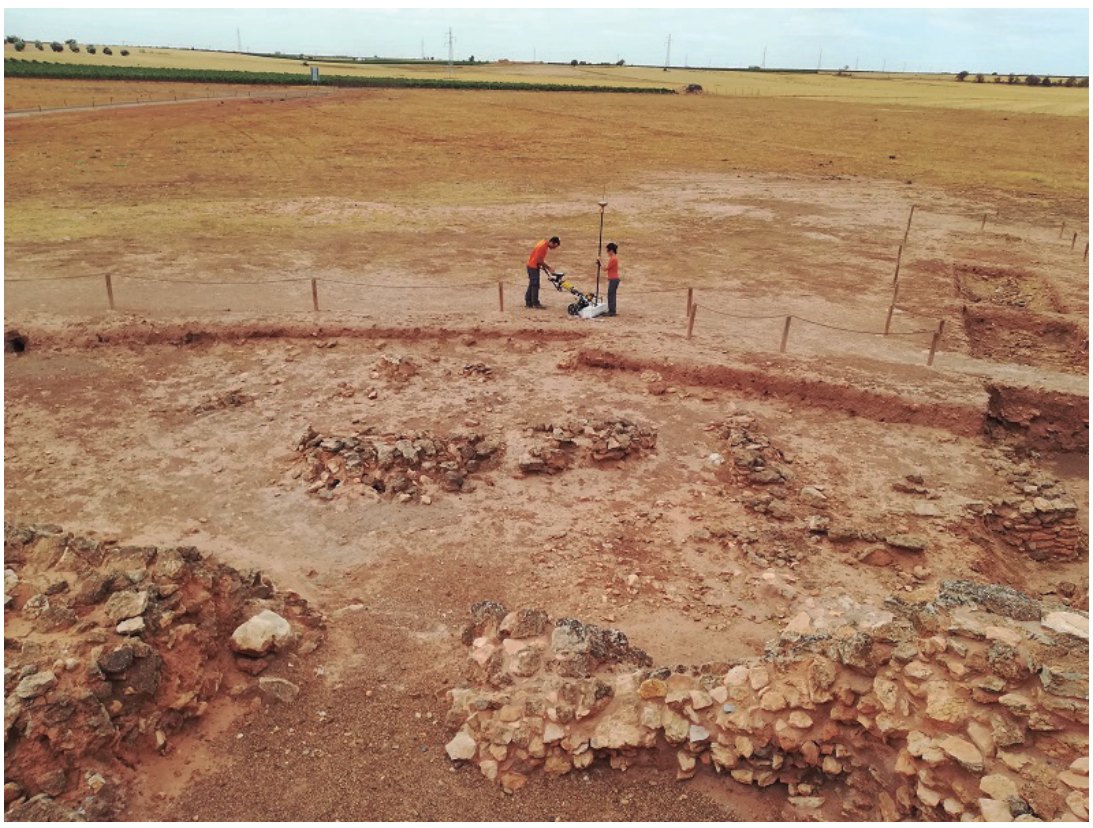

Figura 5. Prospección geofísica en área exterior.

11 La prospección geofísica fue desarrollada por un equipo de la Unidad de Arqueometría del C.A.I de Ciencias de la Tierra y Arqueometría de la Universidad Complutense de Madrid, dirigido por Javier Vallés Iriso. 
el interior, fueron revocados también con barro. Por su parte, las techumbres, a pesar de la ausencia de datos materiales evidentes, han sido plasmadas con vertiente a un agua, compuestas por vigas de madera que van unidas por ramas más finas dispuestas de forma perpendicular, todo ello revestido con elementos vegetales del entorno: carrizos, masiegas o eneas (Mediavilla, Santisteban y Mediato 2012: 13). Mientras, otros elementos perecederos de estas construcciones, verbi gratia puertas y pequeñas ventanas, se ha considerado su fabricación en madera, reproduciendo especies destinadas como material constructivo en el yacimiento: encinas, robles o alcornoques (Nájera y Molina 2004: 198).

En el modelo trazado se ha establecido una imagen de viviendas sencillas, con planta rectangular o de tendencia ovalar, y una sola altura, a falta de información más precisa que apunte hacia edificaciones más elaboradas. Igualmente, se ha adosado a la vivienda una cerca de madera que pudo funcionar para la estabulación del ganado (Nájera et al. 2012: 152).

El registro de improntas vegetales en el interior del recinto vendría a señalar la existencia en determinados tramos de vigas que formarían parte de cubiertas, siendo así dibujadas en la reconstrucción. Sobre la sección superior de la torre central se ha planteado la hipótesis de una techumbre formada por travesaños de madera y cierre final con ramas, aunque corresponde con una valoración no demostrada desde el punto de vista arqueológico.
Por último, el paisaje se ha generado mediante suelos arcillosos y secos, predominantes en este espacio (Mediavilla, Santisteban y Mediato 2012), junto con la presencia de plantas autóctonas y pequeños campos de cereales, cultivos más extendidos en torno a este asentamiento (Nájera y Molina 2004: 202). También se han incluido animales estabulados en los cercados anejos a las viviendas, recogiendo especies relacionadas con la cabaña pecuaria registrada: ovicápridos, bóvidos, équidos y suidos (Nájera et al. 2012: 155).

Para la presentación de la hipótesis virtual de la Motilla del Azuer se ha optado por dos ilustraciones digitales que, a grandes rasgos, tienen como objetivo apreciar los contenidos desde dos puntos de vista diferentes. El primero de ellos consiste en una vista aérea tomada desde el suroeste del yacimiento, mostrando en la ilustración tanto los elementos existentes como los resultados de la prospección geofísica. Mientras, la segunda figura consiste en una perspectiva a nivel de suelo dirigida hacia la Motilla, descubriendo en la composición la propia fortificación, las viviendas y el medio natural vigente (Figura 6). Esta imagen, además de mostrar en detalle las casas y sus sistemas constructivos, origina una empatía más adecuada hacia este bien prehistórico, al establecer una conexión visual más directa con el mismo. De esta forma, se consigue no solo exponer una información patrimonial relevante, sino también generar emociones positivas que refuerzan la acción social de este legado cultural.

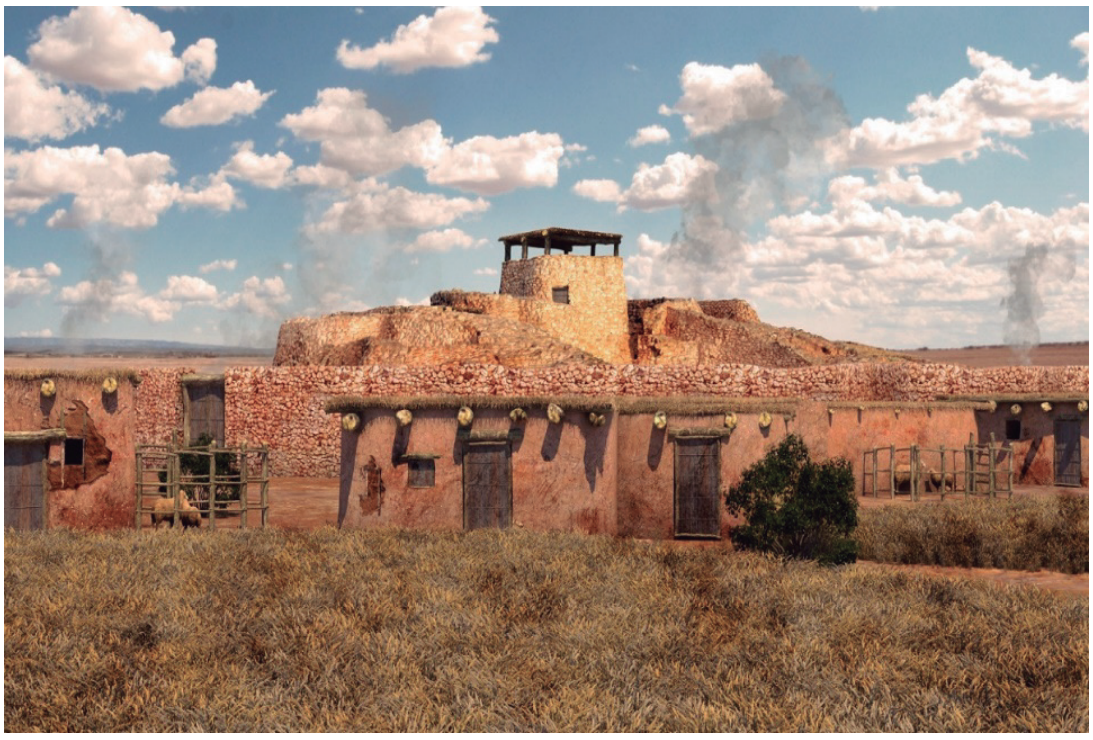

Figura 6. Reconstrucción virtual de poblado y fortificación. Imagen desde el suelo. 
Este tipo de visualizaciones constituyen un instrumento relevante para captar la atención del público, abarcando un amplio alcance en su proyección, desde la comunidad científica hasta personas no especializadas. Supone además una herramienta eficaz para crear una conexión más directa con el espectador, consiguiendo suscitar una sensibilidad más profunda hacia los componentes del patrimonio arqueológico (Tilden, 2009).

\section{Proyecto de realidad virtual: los sistemas head mounted display}

Aunque los trabajos en torno a la RV nos puedan parecer relativamente recientes en el tiempo en verdad se remontan a 1840; fecha en la que Charles Wheatstone inventó el estereoscopio: un aparato que gracias a unas lentes montadas en un visor, y que era colocado delante de los ojos, permitía el visionado de fotografías en 3D.

En 1962 Morton Heilig creó un dispositivo llamado Sensorama, que permitía experimentar con contenidos multimedia utilizando no solo la vista y el oído, sino también el olfato y el tacto, en virtud de la combinación de imágenes estereoscópicas con un campo de visión muy amplio, sonido estéreo, emisor de aromas, una máquina que simulaba el viento y sensaciones hápticas a través de vibraciones. Aunque podría considerarse un HMD (Head Mounted Display), en realidad, el enorme tamaño del dispositivo requería que el espectador colocara su cabeza de forma fija en el visor mientras se sentaba en una silla que formaba parte del mecanismo.

No fue hasta 1968 cuando Ivan Sutherland creó el primer prototipo de HMD que presentaba imágenes artificiales que además respondían a los movimientos de la cabeza del espectador, mostrando la perspectiva correcta de la imagen 3D. En cierto modo, fue el primer intento práctico de resolver el problema asociado a la respuesta de las imágenes a los movimientos del usuario, logrando poner de manifiesto que la capacidad de cómputo necesaria para producir gráficos $3 \mathrm{D}$ en tiempo real requería de dispositivos inexistentes en aquella época.

En 1986 la NASA presentó en la feria electrónica de consumo CES un visor de realidad virtual con pantallas LCD y un campo de visión de $120^{\circ}$, superior incluso a la mayoría de los HMD actuales, que iba acompañado de sensores de movimiento, micrófono, sonido e incluso unos guantes que registraban los movimientos de las manos. La calidad de imagen y velocidad de respuesta a los movimientos fueron todavía insuficientes, pero debido a las prestaciones alcanzadas supuso un grandísimo avance en este sector, pues empezaba a "engañar" al cerebro posibilitando creer al usuario que las imágenes y sonidos que se mostraban formaban parte del entorno.

A finales de los 80 y principios de los 90 se intentó activar la comercialización de modelos de HMDs de VR, pero la tecnología empleada en sus componentes impidió la creación de mecanismos viables y atractivos al público, pues en general la calidad de imagen era muy mala, el tamaño y peso de los dispositivos disparatado y los precios demasiado altos.

El fracaso comercial de la RV paralizó el desarrollo de nuevos dispositivos, a excepción de algunos tímidos intentos, hasta que en el año 2012 Palmer Luckey y su empresa Oculus, presentaron Oculus Rift DK1: un prototipo de un HMD para RV barato (300\$) orientado a desarrolladores de software que se aprovechaban de los avances, miniaturización y abaratamiento de los medios de computación, pantallas y sensores de movimiento (IMU) con ultra baja latencia.

El lanzamiento de Oculus Rift DK1 inició el resurgir de la RV que ha continuado mejorando hasta la actualidad, donde encontramos HMD relativamente baratos y ligeros que incorporan en el mismo dispositivo todo el hardware. Este procedimiento está facilitando la generación de gráficos 3D de alta calidad, sistemas de detección de movimiento posicional con precisión submilimétrica, pantallas de altísima resolución, sistemas de sonido integrados, controladores para las manos con sensores de movimiento e incluso rastreo de sus gestos sin necesidad de guantes.

En función de todos estos avances, para el proyecto de la Motilla del Azuer se ha optado por el dispositivo denominado HTC Vive Pro, que cuenta con controladores por movimiento para las manos (HTC Vive controllers) y los pies (HTC Vive Trackers) (Figura 7). Este dispositivo ofrece unas características muy avanzadas que ha permitido implementar una fórmula verdaderamente inmersiva. Sin embargo, para el éxito del sistema, tan importante como el hardware es el software. 


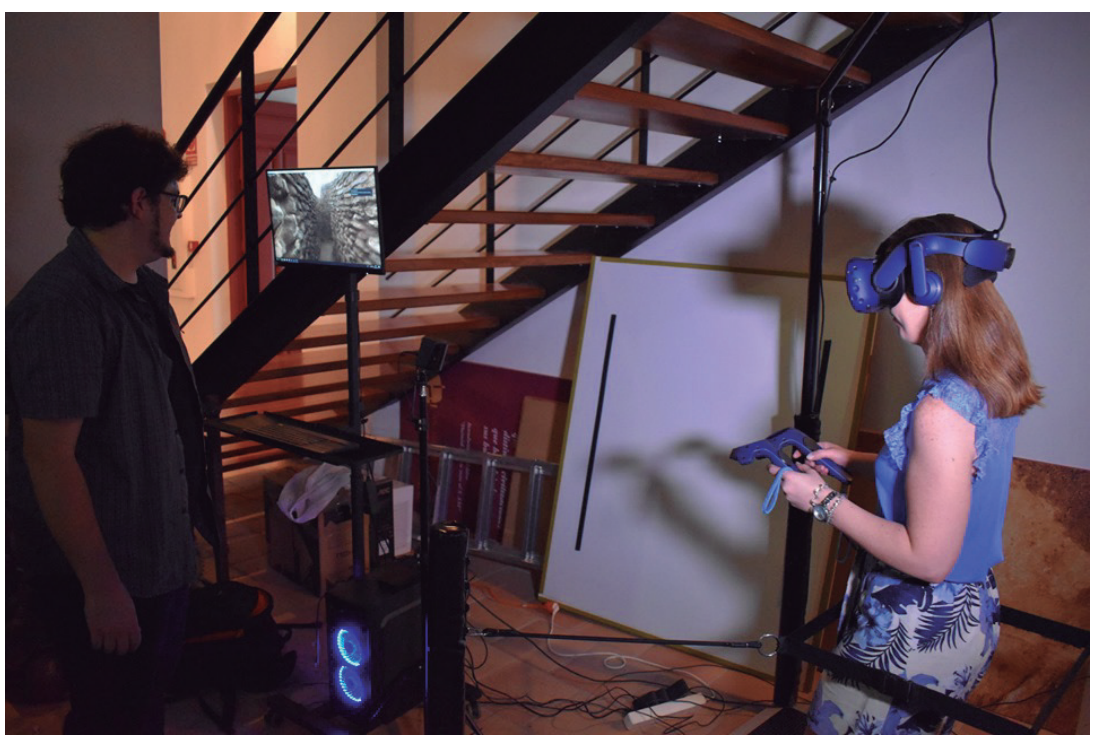

Figura 7. Usuario probando la experiencia de RV en el Museo Comarcal de Daimiel.

\section{Características básicas del software de realidad virtual}

Dado que, tal y como hemos visto, el hardware se encuentra en un punto que posibilita la creación de experiencias de RV de alta calidad, es el software que se ejecuta en estos dispositivos el que debe superar nuevas barreras para incrementar la sensación de inmersividad en el espectador. Sin duda, este ha sido uno de los grandes retos a la hora de diseñar esta experiencia. En ella se ha tenido en cuenta el sistema de locomoción, la mecánica de interacción e interfaces y la calidad gráfica y sonora.

\subsection{Sistemas de locomoción}

La locomoción artificial supone el primer y más importante trámite. Debido a que normalmente las experiencias en RV transcurren en espacios que superan el tamaño de la habitación donde se encuentra el usuario, debe crearse un mecanismo que le permita avanzar más allá de los límites físicos de su entorno. Para los videojuegos clásicos de pantalla normalmente se usan joysticks y botones para trasladar al avatar virtual y la cámara que lo acompaña. En el caso de los videojuegos en primera persona la propia cámara es también la cabeza del avatar.

Por su parte, en RV la cámara es controlada por los desplazamientos reales de la cabeza del usuario cuando este se mueve por la habitación en la que se encuentra, por lo que la posición de la cámara debe coincidir exactamente con la ubicación real de la cabeza del participante. Para ello se utilizan distintos sensores de movimiento inercial (IMU) y también sensores de posicionamiento absoluto que deben funcionar con una latencia menor a $20 \mathrm{~ms}$ o con una precisión submilimétrica, incluso si se realizan maniobras inesperadas. Si la posición o las oscilaciones de la cámara no corresponden con el desplazamiento se produce una disociación entre el sentido de la vista y los movimientos que percibe el sistema vestibular, provocando la aparición de un trastorno denominado "mareo por movimiento artificial" (Akiduki et al. 2003), con efectos muy similares a los producidos por cinetosis (Gavani et al. 2018). De hecho como se ha podido comprobar en ocasiones, este mareo puede llegar a producir náuseas intensas, no sólo durante la propia experiencia sino incluso después de la misma.

Para tratar de reducir esta problemática se ha optado por emplear el programa denominado Natural Locomotion. Este sistema está basado en una locomoción que utiliza sensores en los tobillos que registran el gesto de mover los pies arriba y abajo; asimilándose al gesto de caminar en el sitio. Este procedimiento aumenta considerablemente la sensación de inmersividad, hasta tal punto que puede provocar pérdidas de equilibrio, pues el jugador llega a creer que se encuentra caminando. Por este y otros motivos, en este modelo se ha estimado la ayuda en la visita virtual de un guía externo, de forma que pueda asistir ante este tipo de situaciones anómalas. 


\subsection{Mecánicas de interacción e interfaces}

La segunda barrera a superar en la configuración de la RV ha sido la interactividad. A este respecto, al igual que las paredes físicas delimitan la cantidad de espacio por el que puede moverse el usuario, la ausencia de obstáculos en el mundo virtual puede parecer desconcertante. Si un participante se acerca a una pared virtual y no se produce ninguna interacción podrá atravesarla con las manos y la cabeza, perspectiva que resulta muy poco inmersiva. De igual forma, si los objetos virtuales no colisionan o no se impulsan al empujarlos con nuestras manos, por muy realistas que sean los gráficos o por muy bien que esté realizado el sistema de locomoción, el resultado será bastante decepcionante si no reacciona como lo haría en el mundo real. Por ello, en la Motilla Virtual se han aplicado las propiedades físicas del mundo real al virtual, imposibilitando efectuar acciones improbables como atravesar muros.

\subsection{Calidad gráfica y sonora}

La calidad o el realismo de los gráficos de una experiencia de este tipo no son esenciales en todos los programas, siendo solo imprescindibles en aquellos en los que sea obligatorio alcanzar una simulación completa del mundo real, caso de los yacimientos arqueológicos como la Motilla del Azuer (Figura 8). Es por ello que los gráficos que se han generado en este proyecto han tratado de desarrollar una reproducción lo más fidedigna posible, para lo cual se han empleado técnicas de efectos basadas en propiedades físicas como la metalicidad, la rugosidad o el índice de refracción, entre otras muchas.

El tratamiento de la iluminación es un aspecto complejo, al ser clave en el proceso tratar de recoger el rebote de la luz y su movimiento a través de la geometría del contexto virtual, produciendo sombras, oclusión ambiental o reflejos (Figura 9). En cuanto al nivel de detalle, en RV, al contrario que los juegos de pantallas clásicas, el usuario puede acercarse a los objetos hasta unos escasos centímetros, por lo que resulta inexorable presentar un nivel de detalle en las texturas y las mallas poligonales que no permitan ver las "costuras" del emplazamiento o los objetos virtuales (Figura 10).

Mientras, en lo que concierne a los sonidos se ha apostado por aplicar sensaciones naturales y sintéticas, pero estableciendo como premisa básica que el participante intuya que las fuentes se encuentran bien sincronizadas con los gráficos, es decir, que el sonido se perciba como si viniera de un entorno físico. Estos efectos posicionales se consiguen manipulando el sonido que sale por los auriculares del

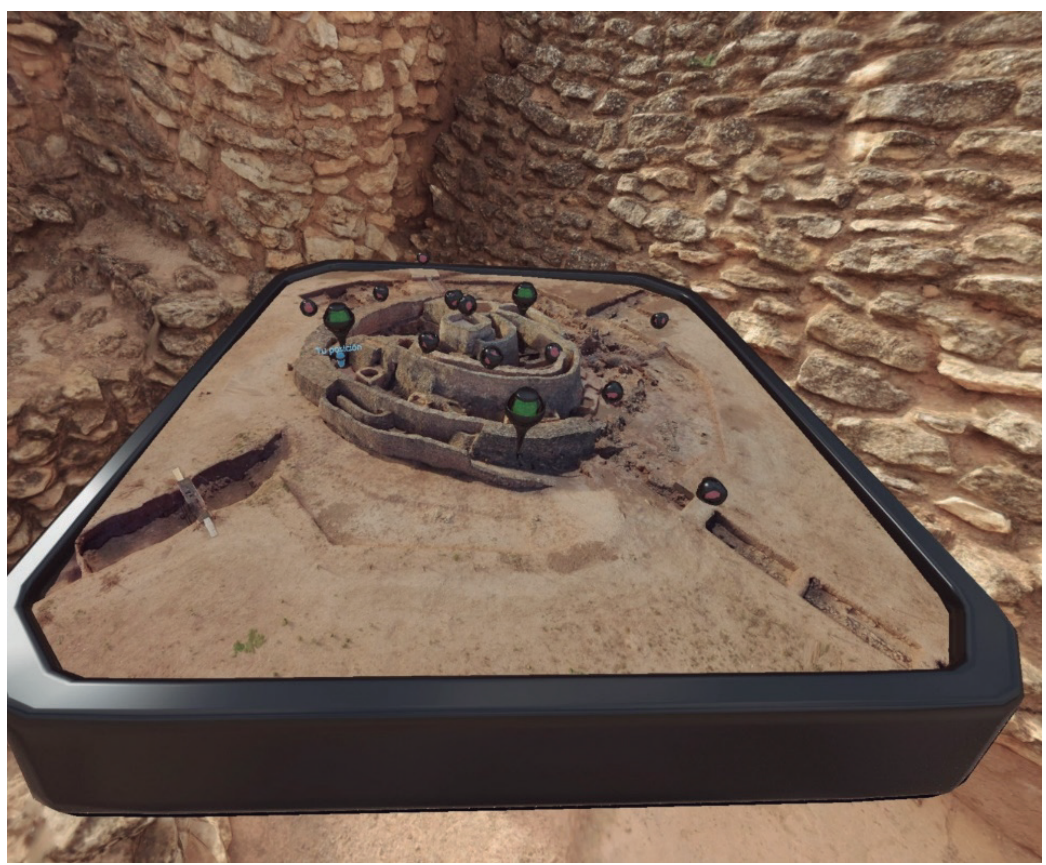

Figura 8. Plano desplegable de la RV. 


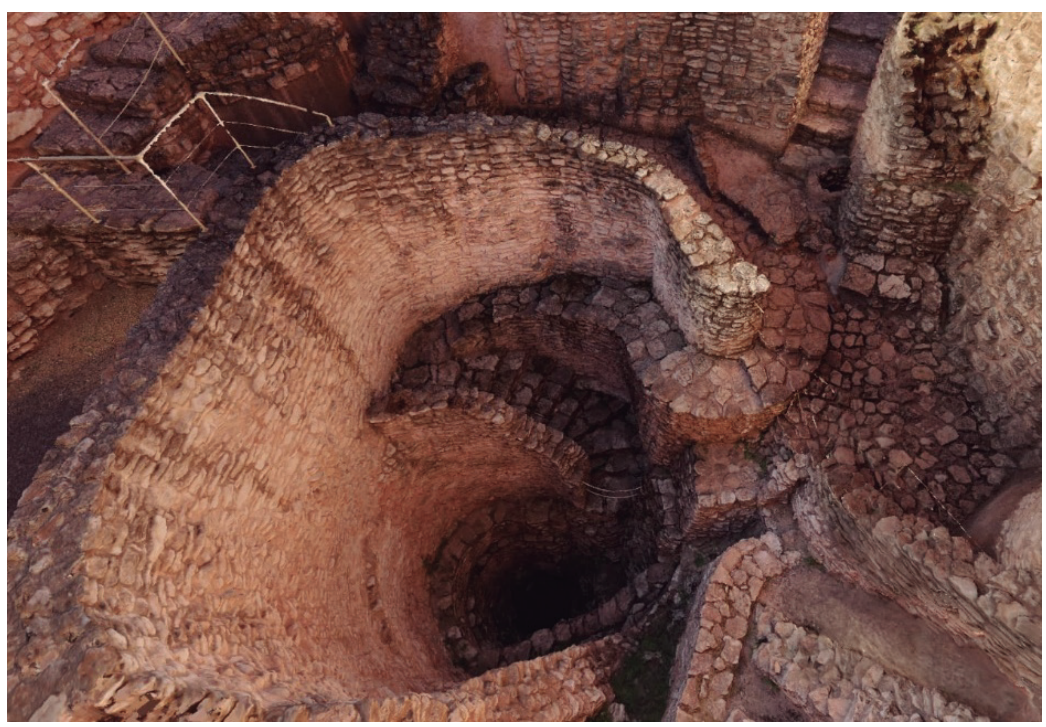

Figura 9. Vista de pozo en RV.

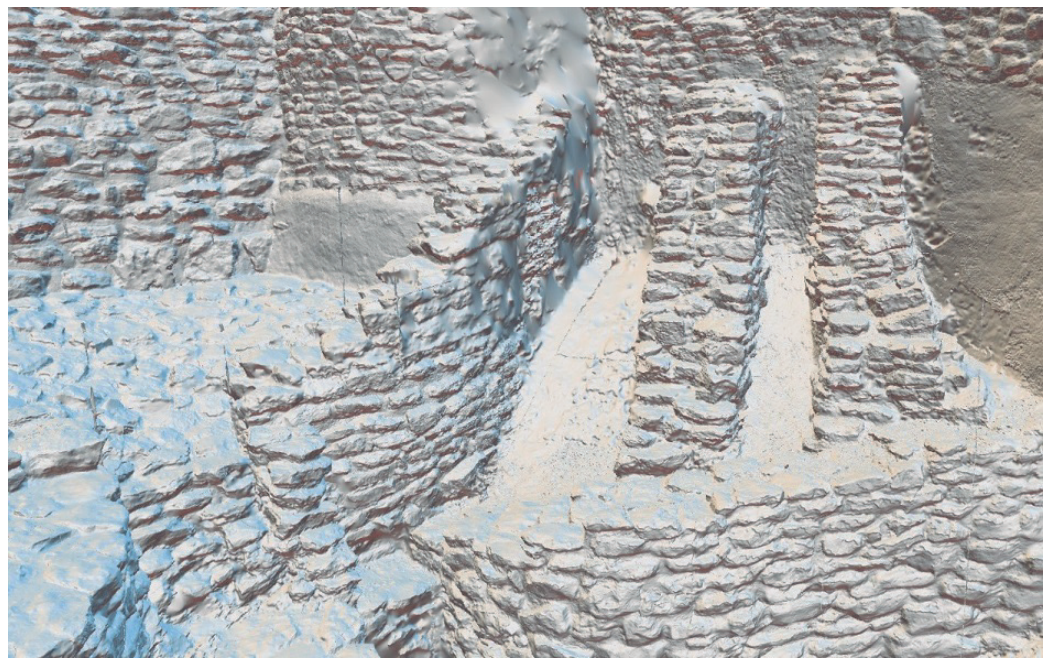

Figura 10. Detalle procesamiento de datos recogidos durante la fase de campo. Perspectiva perteneciente a muros del patio oriental.

HMD, de modo que imite como rebotan las ondas sonoras por el recinto virtual e incluso como se apaga el sonido al atravesar una pared o la propia cabeza del protagonista (Headrelated transfer function).

\section{Conclusiones}

La incorporación de recursos tecnológicos de última generación en la gestión de un ámbito arqueológico como la Motilla del Azuer está suponiendo la integración de numerosas ventajas en su proceso de valorización, potenciando la repercusión de este conjunto y las fórmulas para aproximarse al mismo. Además, esta iniciativa está en relación con una mayor demanda para conocer este bien, dentro de un interés social más intenso sobre el legado arqueológico.

Como se está pudiendo comprobar en este modelo, estos instrumentos están originando una experiencia positiva en diversos planos, tanto para entender la realidad de las comunidades humanas pretéritas como para promover el desarrollo económico, cultural y social de una región. En los mismos términos, está fortaleciendo las actividades para impulsar la democratización cultural, al favorecer la participación de la población en la salvaguarda de 
manifestaciones que forman parte de su vida cotidiana, identidad y tradiciones.

La proyección que está adquiriendo el patrimonio en los últimos años requiere de nuevas fórmulas en su tratamiento, que deben ser concebidas desde enfoques más abiertos que permitan explicar y comprender las relaciones establecidas con su espacio histórico y natural. Asimismo, es conveniente tener presente que una errónea identificación de las riquezas que atesora puede implicar daños irreparables en torno a su definición y exposición. Dentro de estas consideraciones, las nuevas tecnologías están ofreciendo una dimensión innovadora, integral y multidimensional con aportaciones estimables en su exposición.

En los mismos términos, la aplicación de estas técnicas se está caracterizando por la gran diversidad en las opciones disponibles. No obstante, esta pluralidad en las alternativas exige conocer todas las posibilidades tecnológicas y técnicas a nuestro alcance, así como la manera más fácil de desarrollar su implementación (López-Menchero 2012: 75). Además, los procedimientos activados en esta experiencia se han caracterizado por su diseño no destructivo, promoviendo el estudio riguroso y exhaustivo.

En función de las ventajas que ofrecen estos mecanismos, el Ayuntamiento de Daimiel, en el ejercicio de sus responsabilidades en la tutela de la Motilla del Azuer, ha decidido apostar por el empleo de estas herramientas. El objetivo fundamental ha sido favorecer las labores de valorización y promoción de este monumento prehistórico excepcional.

Este programa, denominado Motilla Virtual, ha permitido incluir una serie de procedimientos metodológicos basados en propuestas como el escaneado digital, el termografiado del área arqueológica, el análisis geofísico del subsuelo, la reconstrucción virtual del hábitat o el funcionamiento de una experiencia de RV. Todos estos trabajos se han diseñado dentro de una organización global orientada a avanzar en la investigación, obteniendo datos novedosos sobre el poblamiento y el modus vivendi de estas gentes; la conservación de sus vestigios, enfocando los proyectos de restauración, y la difusión de sus elementos. Entre otros resultados, es destacable que estas actividades están posibilitando una repercusión intensa del yacimiento, ampliando los colectivos que pueden conocer sus riquezas, a cambio de una inversión relativamente reducida.

La utilización de estos instrumentos ha abierto un abanico de oportunidades para la comprensión de esta entidad patrimonial, habilitando fórmulas heterogéneas para aproximarnos a ella. Grosso modo, los resultados alcanzados han significado un avance considerable en su valorización integral: facilitando su interpretación y documentación, adecuando las acciones necesarias de restauración, e impulsando su divulgación, pues ha configurado una alternativa viable a la visita in situ. Esta última mejora supone un beneficio sugerente para un recinto en el que debido a sus peculiaridades los recorridos son realizados mediante cupos reducidos de personas (Torres 2020: 279).

De igual manera, la activación de estos medios aporta sinergias económicas interesantes: venta de artículos para su comercialización, verbi gratia réplicas tridimensionales a diferente escala; estrategias atractivas para su promoción como destino turístico, o incluso campañas publicitarias de amplio espectro. Además, la ubicación espacial del dispositivo de RV en el Museo Comarcal representa un reclamo para el tejido económico local, al atraer a potenciales usuarios hacia el interior de su núcleo urbano.

En definitiva, la gestión de un recurso patrimonial como la Motilla del Azuer debe implicar el fortalecimiento de todos aquellos valores y símbolos que atesora, al suscitar un valor añadido que despierta expectativas favorables hacia el mismo. En este sentido, la integración de herramientas tecnológicas en su administración constituye una iniciativa muy beneficiosa en su misión, al proporcionar un estímulo en ámbitos como el económico, educativo y cultural, pero sobre todo el social, pues como señalan $\mathrm{M}^{\mathrm{a}}$ Ángeles Querol y Belén Martínez (1996: 20) lo que convierte al patrimonio arqueológico en importante es su incidencia social.

\section{Bibliografía}

Akiduki, H., Nishiike, S., Watanabe, H., Matsuoka, K., Kubo, T. y Takeda, N. (2003): "Visual-vestibular conflict induced by virtual reality in humans", en Neuroscience Letters, 340(3), pp. 197-200.

Angulo, M.I. (2018): "Conservación y restauración en el yacimiento arqueológico de la Motilla del Azuer, campañas 2015 y 2016”, en IV Jornadas de Historia de Daimiel. Ayuntamiento de Daimiel, pp. 31-44. 
Gavgani, A.M., Walker, F.R., Hodgson, D.M. y Nalivaiko, E. (2018): “A comparative study of cybersickness during exposure to virtual reality and "classic" motion sickness: Are they different?", en Journal of Applied Physiology, 125(6), pp. 1670-1680. https://doi.org/10.1152/japplphysiol.00338.2018.

García, M., de la Calle, M. y Mínguez, M.C. (2014): "La capacidad de carga turística del conjunto arqueológico de Carmona", en Investigar, conservar difundir: el Proyecto Guirnaldas en el Conjunto Arqueológico de Carmona. Sevilla: Secretariado de Publicaciones de la Universidad de Sevilla. pp. 171-188.

Jiménez, S.A., Al-Oumaoui, I., Nájera, T. y Molina, F. (2008): "Salud y enfermedad en La Motilla del Azuer: una población de la Edad del Bronce en La Mancha”, en Revista Española de Antropología Física, (28), pp. 57-70.

López-Menchero, V.M. (2012): Manual para la puesta en valor del patrimonio arqueológico al aire libre. Ediciones Trea.

López-Menchero, V.M. (2013): La musealización del patrimonio arqueológico in situ: El caso español en el contexto europeo. British Archaeological Reports International Series.

López-Menchero, V.M. (2013): "International Guidelines for Virtual Archaeology: The Seville Principles", en C. Corsi, B. Slapšak, \& F. Vermeulen. (Eds.), Good Practice in Archaeological Diagnostics: Noninvasive Survey of Complex Archaeological Sites (pp. 269-283). Springer International Publishing Switzerland. https://doi.org/10.1007/978-3-319-01784-6_16.

López-Menchero, V.M., Flores, M., Vicent, M. y Grande, A. (2017): "Digital Heritage and Virtual Archaeology: An Approach Through the Framework of International Recommendations", en M. Ioannides, N. Magnenat-Thalmann, y G. Papagiannakis, (Eds.), Mixed Reality and Gamification for Cultural Heritage, Springer International Publishing, pp. 3-26. https://doi.org/10.1007/978-3-31949607-8_1.

López-Menchero, V.M. y Grande, A. (2011): "Hacia una Carta Internacional de Arqueología Virtual. El borrador SEAV”, en Virtual Archaeology Review, 2(4), pp. 71-75. https://doi.org/10.4995/var.2011.4558.

Lužnik-Jancsary, N., Horejs, B., Klein, M. y Schwall, C. (2020): "Integration and workflow framework for virtual visualisation of cultural heritage. Revisiting the tell of Çukuriçi Höyük, Turkey", en Virtual Archaeology Review, 11(23), pp. 63-74. https://doi.org/10.4995/var.2020.13086.

Martín, M., Molina, F., Blanco, I. y Nájera, T. (2004): “Actuaciones y restauración en la Motilla del Azuer (Daimiel, Ciudad Real)”, en R. García Huerta y J. Morales Hervás (Coords.), La Península Ibérica en el II mil. a.C.: poblados y fortificaciones. Cuenca: Ediciones de la Universidad de Castilla-La Mancha, pp. 215-232.

Mediavilla, R., Santisteban, J.I. y Mediato, F.J. (2012): "Las Tablas de Daimiel en el contexto de la cuenca alta del Guadiana", en R. Mediavilla (ed.) Las Tablas de Daimiel: agua y sedimentos. Madrid: Instituto Geológico y Minero de España, pp. 3-18.

Merhav, R. y Killebrew, A.E. (1998): "Exponer es exponerse: para bien y para mal", en Museum Intemacional, $\mathrm{n}^{\circ}$ 200, 50:4, pp. 15-20.

Nájera, T. y Molina, F. (2004): "Las motillas: un modelo de asentamiento con fortificación central en la Llanura Manchega", en R. García Huerta y J. Morales Hervás (Coords.), La Península Ibérica en el II mil. a.C.: poblados y fortificaciones. Cuenca: Ediciones de la Universidad de Castilla-La Mancha, pp. 172-217.

Nájera, T., Molina, F., Cámara, J.A., Afonso, J.A. y Spanedda, L. (2019): “Análisis estadístico de las dataciones radiocarbónicas de la Motilla del Azuer (Daimiel, Ciudad Real)", en Cuadernos de prehistoria y arqueología de la Universidad de Granada, 29, pp. 309-351. https://doi.org/10.30827/ cpag.v29i0.9780.

Nájera, T., Jiménez, S.A., Molina, F., Delgado, A. y Laffranchi, Z. (2012): "La aplicación de los métodos de la antropología física a un yacimiento arqueológico: la Motilla del Azuer", en Cuadernos de prehistoria y arqueología de la Universidad de Granada, 22, pp. 149-182. https://doi.org/10.30827/cpag.v22i0.2422.

Nieto, G. y Sánchez-Meseguer, J. L. (1988): Bases para la sistematización del estudio de la Edad del Bronce en La Mancha, en Actas del I Congreso de Historia de Castilla-La Mancha, II, pp. 221-227.

Noardo, F. (2018): Architectural heritage semantic 3D documentation in multi-scale standard maps, en Journal of Cultural Heritage, 32, pp. 156-165. https://doi.org/10.1016/j.culher.2018.02.009.

Peña, J.A.; Teixidó, M ${ }^{\mathrm{a}}$. T., Nájera, T., Molina, F. (2009): Obtención de imágenes goerrádar 3D en el yacimiento arqueológico de la Motilla del Azuer (Daimiel, Ciudad Real)", en Cuadernos de prehistoria y arqueología de la Universidad de Granada 19, pp. 361-378. Buscar https://doi.org/10.30827/cpag. v19i0.195. 
Querol, Mª A. y Martínez, B. (1996): La gestión del patrimonio arqueológico en España. Alianza, Madrid. Tilden, F. (2009): Interpreting our heritage. The University of North Carolina Press.

Torrejón, J., Moya, P.R., Galeano, M., Díaz, A., Vallés, J., Hernández, D., Matesanz, J.F., Pérez, C., (2019): Una hipótesis virtual para Peñaflor, aldea fortificada de repoblación medieval en la Submeseta Sur de la península ibérica", en Arqueología Iberoamericana, 42, pp. 9-13.

Torres, M. (2015): "La Motilla del Azuer: un yacimiento de interés arqueológico en Daimiel (Ciudad Real)", en III Jornadas de Historia. Ayuntamiento de Daimiel, pp. 15-30.

Torres, M. (2016): "De motillas a poblados en altura: el poblamiento de La Mancha Occidental en el II milenio a.n.e.”, en F. Alía, J. Anaya, L. Mansilla, y J. Sánchez (coords.), II Congreso Nacional Ciudad Real y su provincia. Ciudad Real: Instituto de Estudios Manchegos, pp. 42-61.

Torres, M. (2020): "La Motilla del Azuer y el modelo de gestión del patrimonio cultural del Ayuntamiento de Daimiel 2013-2017”, en J. Onrubia, V.M. López-Menchero, D. Rodríguez, y J. Morales (eds.), LEGATUM 2.0. Musealización y Puesta en Valor del Patrimonio Cultural: I Congreso Internacional. Ediciones de la Universidad de Castilla-La Mancha, pp. 273-284. https://doi.org/10.18239/ congresos 2020.22.28

Torres, M., Angulo, M.I., Álvarez, H. y Rodríguez, D. (2021): "El patrimonio de Daimiel a través de la arqueología: investigación, rehabilitación y difusión", en $V$ Jornadas de Historia de Daimiel. Ayuntamiento de Daimiel, pp. 267-283.

Weech, S., Moon, J. y Troje, N.F. (2018): "Influence of bone-conducted vibration on simulator sickness in virtual reality", en PLOS ONE, 13 (3), pp. 1-21. https://doi.org/10.1371/journal.pone.0194137

World Tourism Organization (2001): Cultural heritage and tourism development. A report on the International Conference on Cultural Tourism. Madrid, World Tourism Organization. 
